\title{
Influence of Psychological Empowerment on Organizational Commitment among Medical Employees in a Hospital Setting
}

\author{
Ali Kebriaei ${ }^{1, a^{*}}$, Meysam Rakhshaninejad ${ }^{2, b}$ and Zahra Afshari ${ }^{3, \mathrm{c}}$
}

${ }^{1}$ Department of Public Health, School of Health, Kashan University of Medical Sciences, Qotb-eRavandi Boulevard, Kashan, Iran.

${ }^{2}$ Zabol University of Medical Sciences, Zabol, Iran.

${ }^{3}$ Zabol University of Medical Sciences, zabol, Iran.

Email address: ${ }^{2}$ kebria_noosh@yahoo.com ${ }^{b}$ m.rakhshani6@yahoo.com

czahraafshari1526@yahoo.com

Keywords: Psychological empowerment, organizational commitment, Employed,

ABSTRACT. Introduction: people within organizations are a key fo tor fo efficis $\%$. Thus employee empowerment has become a popular management str tes. The stu aimed to investigate the relationship between psychological empowerment ad orga tional commitment among medical staff of a hospital in Zahedan city.

Methods: This cross sectional study was carried out 20 A randem sample of 172 medical employees in Khatam-ol-Anbia hospital at Zahed city was lected and responded to items of the questionnaires using a 7-point Likert sf ale ranging from 1 to 7 . For measuring psychological empowerment and organizational com nitment, Michra \& Spreitzer's scale and Meyer and Allen's questionnaire were used. A higher s means a higher degree of psychological empowerment or organizational commitment. Analysis on orrie out using SPSS.

Results: The level of organizationa mmitment and psychological empowerment significantly were higher than average. Ther was rificant positive relationship between employees' empowerment and their commitment organ ation. Psychological empowerment was a significant predictor of organizat onta ommitn ent $(\beta=.524)$. Out of the five dimensions of empowerment three dimensions signi cant pre ctors of commitment and explain $37.1 \%$ of the variance in commitment.

Conclusions: Due to pe positiv fluence of psychological empowerment on organizational commitment, programs to n-service ducation should focus on facilitating psychological empowerment to imp ye a increase organizational commitment. Also, since impact of employees psycho ogical empow cht on organizational commitment partially supported, there are other variabl that 1 uence the organizational commitment.

\section{1.}

$\mathrm{P}$ ople rithin o anizations are the key factor for survival in a highly competitive envirou nt factor in the efficiency of their organizations [1]. yet, in our time employee organizations report feeling isolated, undervalued, dehumanized, and exploited[2]. Regarding th sues, one of the most useful techniques to raise staff productivity and the best use of capabilities and capacities of individuals and groups in line with organizational objectives is empowerment $[3,4]$.

In recent years many efforts have been made to improve organizations that mostly focused on areas such as reduction of hierarchy and bureaucracy, forming dynamic groups, participation in decision-making at the lowest level of organization and in other words empowerment of employees[1].Thus, employee empowerment has become a popular management strategy in today's human resource management and a trend in all organizations[5] and in recent years, more than $70 \%$ of organizations have adopted some kind of empowerment initiative in their workforce[6].

Empowerment is defined as individual beliefs of employees about their role in relation to the organization [6]. Between the two concepts of empowerment, structural and psychological [7], this 
research is focusing on psychological empowerment. Psychological empowerment refers to a set of psychological states that are necessary for individuals to feel a sense of control in relation to their work role [7, 8]. It is revealed in the five feelings of meaning, competence, self- determination, confidence, and impact [6]. This psychological perspective views empowerment as organic or bottom-up processing in which empowerment is achieved only when psychological states produce a perception of empowerment within the employee. It is not the conditions of the work context but the reactions of the employee to these conditions that in turn, influence their organizational behavior [9].

Possible benefits of employee empowerment identified in the literature and the researches include stronger motivation, [7] higher job satisfaction, [10,11] greater effectiveness [8, 12]; lower levels of turnover [7]; organizational citizenship behavior [13]; and organizational commitment [4, $11,14,15]$.

Organizational commitment is a psychological state that describes th relationsh of employees with the organization for which they work and that has deduction for decisi $h$ to continue with the organization [16]. Organizational commitment is conside ed as a ke terr inant of organizational outcomes such as performance [17, 18]; controlle abs aeism 19] and organizational citizenship behavior [20]. For this reason, employee $\mathrm{co}$ m. contin to be one of the most exciting topics for both executives and researchers [21]

However, despite the numerous researches on the r a ship bet $n$ psychological empowerment and organizational commitment in various or zation settings, doing research on these topics in hospitals in Iran seems to be still necess y oucause fin the results of different empowerment studies conducted in different settings a inconsistent. Fo example, Moynihan and Pandy found a significant negative correlation etween en ployees' empowerment and organizational commitment [22] and Mastracci found significa t positive correlation between employees' empowerment and organizational ammitmen. natnagar [24] and Chen and Chen [25] in their studies concluded that some of the rerment dimensions were positively related to organizational commitment and some other lim were negatively or not related to organizational commitment. Secondly due to o ferent culture and organizational structure the results of those studies are not apr icab in an ec tern society like Iran. Thirdly a hospital is an institution which has the most i- antia and important role in society [26]. Fourthly hospitals in Iran currently facing many is in or. ommitment to the organization [27]. And finally in past no similar study har onducted nedical staff as a group in Iran. Therefore, little is known regarding if and how pe cho ical empo verment is related to organizational commitment and the mechanism of this re tionship t clear in the context in Iran.

Based on th rationale, the ady aims to investigate the actual picture of the relationships between psych gical apowerment and its five dimensions with organizational commitment among medical st. Khata -ol-AnbiaHospital in Zahedan city in I.R. Iran.

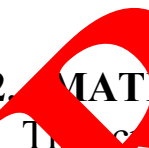

\section{RIALS \& ND METHODS}

onal study was carried out in spring 2013. The population of the study was 308 medic. 'mployees (i.e all of staff that involved in patients' care such as physicians and nurses) in Khatam-or Abia hospital at Zahedan city. Using cochran formula for sample size calculation in finite populations the sample was made up of 172 of medical employees selected by simple random sampling technique. The participants completed the questionnaires anonymously. Finally, 150 questionnaires $(88.2 \%)$ were correctly filled out and gathered for analysis.

In this study, in the first piece of the questionnaire respondents gave their demographic data. For measuring psychological empowerment, Mishra \& Spreitzer's scale was used. Spreitzer demonstrated the internal consistency and test-retest reliability of the dimensions of psychological empowerment in a work context [7].

It consists of 15 items regarding psychological empowerment features, which are grouped into five dimensions: (1) meaningfulness (or meaning); (2) competence; (3) self determination (or selection); (4) impact; and (5) confidence. Each of the five dimensions contains three items. 
Meaning refers to work value of a work objective, judged in connection with individuals' own ideals or standards. Competence or self efficacy contains an individual's belief in his or her capability to do activities with skills. Self determination or selection is an individual's sense of having an option in starting and regulating procedures. Impact discloses the feeling that a person thinks he can influence the outcomes of an assignment. Finally, the sense of confidence means that the staff is sure to be behaved fairly [6].

Organizational commitment was measured using a shortened form of the Meyer and Allen's organizational commitment questionnaire [19], with 5 items. The Allen \& Meyer's organizational commitment questionnaire (OCQ) was selected for this study as it is a widely-used, reliable and validated scale of organizational commitment [16].

Participants responded to items of the two questionnaires using a 7-point Likert saer ranging from 1 (strongly disagree) to 7 (strongly agree). The total score ranges from 15 to for psychological empowerment and from 5 to 35 for organizational commitm question ires respectively. A higher score means a higher degree of psychologicor en vermen or organizational commitment.

The statements of original questionnaires were translated into Fars Three yerts the field inspected the questionnaire to ascertain its consensual validity and th $\mathrm{g}$ of st ements was also simplified. Lastly a pilot test was conducted with 30 respo aents and al a justment was made accordingly. Reliability of the questionnaires was 0.82 psycholos al empowerment questionnaire (meaning $=0.726$, competence $=0.740$, self a term in $=0.750$, confidence $=$ 0.815 and impact $=0.749$ ), and 0.782 for organizational orm itment so Asing Cronbach's alpha coefficient. According to Hair et al. Cronbach's alph coefficients eque to or more than .7 has adequate reliability [28].

Descriptive statistics (mean and standard deviat were ured to study the distribution of data. One-sample t-test, correlation, simple megression altiple regressions were used to analyze data. A one-sample t-test was perform ampare the sample mean to the mean of the similar previous study [29]. Pearson's correl ior an cient was achieved to measure how variables are related. Simple linear reorssion wa conducted to study the impact of psychological empowerment on organizational co nmt nt. Step vise multiple regression analysis was conducted to determine whether each di von of psychological empowerment affects organizational commitment. Total psycholoo en wermu and its five dimensions served as independent and organizational commitmen depende ariables in regression analyses. Assumption of normality, and multicollinearity ere hecked. nalysis was carried out using SPSS for Windows (version16.0). $P$ valu hos than 95 were considered statistically significant.

3. RESUL

The results $s$ the $m$ an age of the respondents was $30.17 \pm 7.6$ years. 79.3 percent of them were fep ar nd the were males. $70.7 \%$ of the participants were married and $29.3 \%$ were single $0.7 \%$ f subject had a high school diploma. $89.3 \%$ of them had a college level education.

T. Mat the mean of organizational commitment, psychological empowerment and the five $\mathrm{d}_{\mathrm{h}}$ nsions of psychological empowerment were on the higher side. One-sample t-test implies that $t$ means are significantly higher than the average of the similar previous study. The highest and lowest mean were in competence and confidence dimensions respectively (Table 1). 
Table 1: Descriptive and analytic statistics of independent variables and dependent variable.

\begin{tabular}{|c|c|c|c|c|c|c|c|}
\hline Variables & Min. & Max. & Mean & $\begin{array}{l}\text { Std. } \\
\text { Deviation }\end{array}$ & $\begin{array}{l}\text { Mean(previous } \\
\text { study) }\end{array}$ & $\mathrm{t}$ & Sig \\
\hline Meaning* & 3 & 21 & 17.11 & 3.85 & 13.92 & 16.231 & .000 \\
\hline Competence* & 3 & 21 & 18.13 & 3.02 & 14.22 & 24.850 & .000 \\
\hline Self determination* & 3 & 21 & 13.49 & 5.44 & 12.43 & 3.360 & .001 \\
\hline Impact* & 3 & 21 & 13.12 & 5.52 & 11.94 & 2.486 & .014 \\
\hline Confidence* & 3 & 21 & 13.04 & 5.67 & 11.93 & 2.246 & .026 \\
\hline Psychological empowerment* & 27 & 102 & 74.89 & 16.75 & 64.44 & 10.886 & .000 \\
\hline Organizational commitment** & 5 & 35 & 22.45 & 8.14 & 19.81 & 3.693 & 000 \\
\hline Valid N & 150 & & & & & & \\
\hline
\end{tabular}

In the table 2, internal correlation of research variables have been provide the Thest lowest correlations with organizational commitment were observed in in and competence dimensions respectively. As it is observable there were significar positiv orrela ons between psychological empowerment and its dimensions with organizati commitm Aence it can be assessed in a regression model precisely. To investigate these reh ary findings further, simple and Stepwise multiple regression were applied betwee penden riable and independent variables.

Table 2: Correlation of psychological empowerme and its dim hsions with organizational commitmen

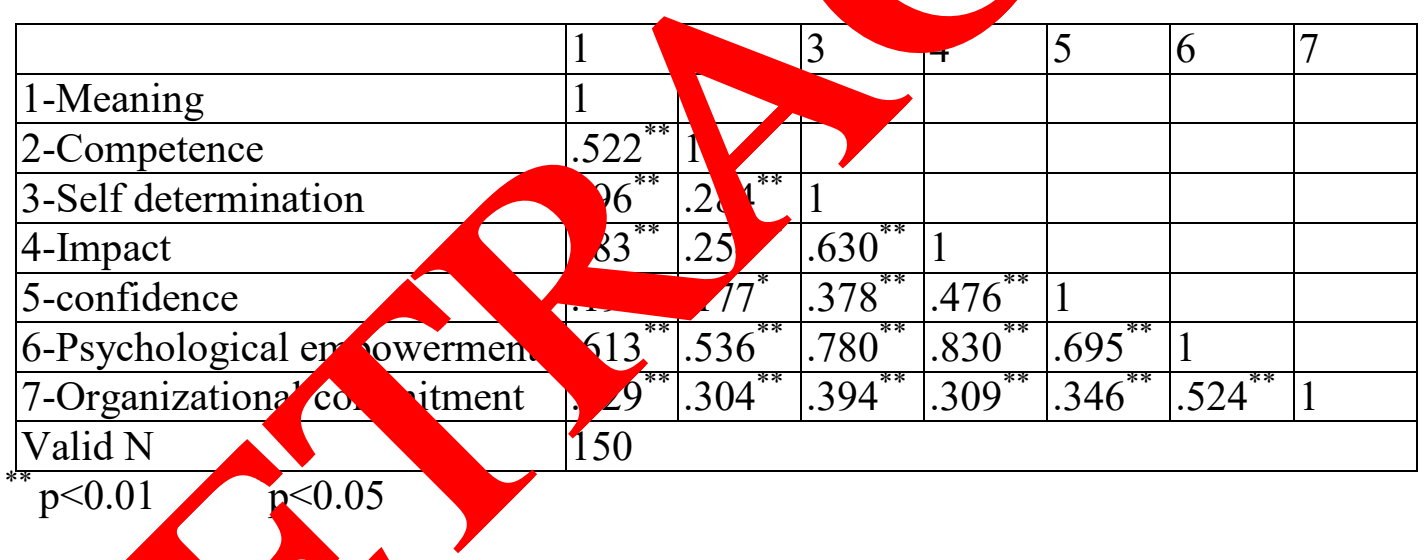

The results of 'ple res ession indicated a significant positive impact of employees' empowerm on co amitment to the organization. Psychological empowerment was a signific ant $\mathrm{pr}$ ictor on anizational commitment $(\beta=.524, \mathrm{~F}=55.89, \mathrm{p}=.000)$.

Then wis multinle regressions were applied to determine the role of the five dimensions of

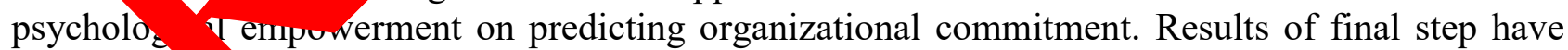
been prese in table 3.It show that three dimensions of empowerment (Meaning, Self determination and confidence) are significant predictors of commitment and all the three entered dimensions in model together explain $37.1 \%$ of the variance in commitment. Meanwhile, out of them meaning has the strongest influence $(\beta=.435, \mathrm{P}=0.000)$ on commitment.

Table 3: The result of stepwise multiple regressions between dimensions of psychological empowerment and organizational commitment

\begin{tabular}{|c|c|c|c|c|c|}
\hline Independent variables & $\mathrm{R}^{2}$ & $\beta$ & $\mathrm{F}$ & $\mathrm{t}$ & Significance \\
\hline Meaning & \multirow{3}{*}{.371} & .435 & \multirow{3}{*}{28.748} & 6.30 & .000 \\
\hline Self determination & & .195 & & 2.66 & .009 \\
\hline confidence & & .187 & & 2.63 & .009 \\
\hline
\end{tabular}

Dependent variable: organizational commitment 


\section{DISCUSSION}

In the current study effects of psychological empowerment and its dimensions on organizational commitment were examined. The findings indicated that employees' psychological empowerment and organizational commitment were significantly higher than mean. The study showed that only three dimensions of psychological empowerment significantly influenced organizational commitment.

In line with some other studies [30-33] and inconsistent with others ones [21, 34, 35], in our study staffs' psychological empowerment was higher than average. Yet some plans to raise employees' perceptions of empowerment need to be initiated. Because empowerment is not an enduring personality trait generalizable across all situations, but rather a set of cognitions shaped and changed by a work environment [36], based on questionnaire items, the managementan help to build an atmosphere and organizational culture of open communication that pery it pers el to express their views, take in to account others' opinions, and support questioning f feedbac hat increase employee empowerment especially in Self determination, Impact à Confic nce dimensions. In this regard, also designing and implementing programs for he hospita nar, ers to take on new roles as coaches and facilitators, can also improve he ley of e ployees' psychological empowerment. In turn, such a culture and arranger ant cibutes $o$ nurturing organizational commitment.

Consistent with the findings in earlier studies $[11,37,3 \mathrm{~s}$ dimensio of psychological empowerment showed positive and significant relationships orga tional commitment (Table 2). It can be concluded that the more psychologically be mimponered an loyee; the more likely he/she will be committed to the organization.

Similar to other researches $[37,39,40]$ the resu of the stu $y(\beta=0.524, p$ value $=.000)$ clarify that the psychological empowerment as a who has a po itive impact on organizational commitment. However, despite the correlatio of all asp sychological empowerment with organizational commitment (Table 2), and in with other studies [21, 29, 30, 38] that found only two or three dimensions predicted or nniz atm commitment, in our study only three of the five dimensions namely the meaning, elf determination and confidence predicted organizational commitment. The $p$ ossib reason or why competence and impact dimensions of psychological empowerment no significantly influence the level of organizational commitment could be cultura . fer s anu suld be investigated in further research.

In other words, the $r$ ondents $a_{\text {. }}$ oyed that their organizational commitment will increase if the type of work they erto inherentl possesses certain intrinsically motivating characteristics, remarkably skill var ty, task ificance, and feedback. If hospital employees feel the task is meaningful and is adding value to $\mathrm{cm}$, they would be more committed. In addition organizational commitment $y$ incre when they are given the autonomy to make decisions about work processes. They give th ir commitment to the hospital when they are confident that the managem tes the on 1 butions and feel secured and supported in the organization.

$T$,e thi aforen ationed dimensions together explain $37.1 \%$ of variance of commitment $(\mathrm{F}=28$. 5 affect the Tnizational commitment.

Amons three factors of psychological empowerment (table 3), meaning $(\beta=.435 \mathrm{p}=.000)$

had the strongest effect on respondents' organizational commitment. It means that the sense of employees about the meaningfulness of their duties is the most important for predicting organizational commitment. This result is consistent with work of Jha [21].

In conclusion, this study will help the hospital setting in improving their employees' commitment to the organization and also contribute in literature. Although mean of the respondents' empowerment and commitment were higher than average, yet there are opportunities for improvement in all five dimensions of psychological empowerment especially in confidence, Impact and Self determination dimensions. Therefore hospital management can identify and continue innovative policies in order to raise employees' empowerment and in turn their commitment so that hospital can provide safe, effective and high quality care for the patients. Since 
the three dimensions of empowerment only explain $37.1 \%$ of variance of commitment, it can be concluded that impact of employees psychological empowerment on organizational commitment partially supported and there are other variables besides empowerment that influence the organizational commitment.

There are a few limitations in the study. The research was a questionnaire based one and depended on respondents' understanding. Study data were collected from a single hospital. Therefore, findings may not be generalized to other healthcare settings without caution.

Replication of this research in other hospitals and healthcare setting can help to validate the current results. In addition further studies are required to study what variables moderate or mediate the impact of empowerment on commitment.

\section{ACKNOWLEDGMENT}

We are grateful to the respondents who participated in the study and Mrs. Mar $\mathrm{m}$ Kebria for reviewing the manuscripts. We appreciate Khatam-ol-Anbia hospital authon, for leir managerial support.

\section{References}

[1] Taktaz B, Shabaani S, Kheyri A, M. R. The Relation between ychologic Em owerment and Performance of Employees SINGAPOREAN Journ a business Économics and management studies. 2012;1(5):19-26.

[2] Lee PC. Cognition and affect in leader behavior the effects of irituality, psychological empowerment, and emotional intelligence on the otivation to lead: Regent University; 2005.

[3] Lau WKJ. Empowerment of non-academic personne higher e ucation: exploring associations with perceived organizational support f innovatio organizational trust: University of Iowa; 2010.

[4] Dashgarzadeh K, SaremiRad S. Examine the e'ations 1 p between psychological empowerment and organizational commitme mobil communications company. Journal of Public Management. 2010;1(3):60

[5] Pitts DW. Leadership, en public organizations. Review of Public Personnel Administration. 2005 5(1):5-28.

[6] Spreitzer GM. Taki s sto A reviev of more than twenty years of research on empowerment at work. Hand 1 of orgà atignal behavior. 2008:54-73.

[7] Spreitzer G Psyc logical Empowerment in the workplace: Dimensions, Measurement, and Validation. caden of Management Journal. 1995;38(5):1442-62.

[8] Sprei M, D immi ss (Ed.): nousand Oaks, CA: Sage Publications.; 2008.

[9] Kno van ange R. Innovative behaviour: the effect of structural and psychological empo ment on nurses. Journal of Advanced Nursing. 2009;65(2):359-70.

[10] Laschinger HKS, Finegan J, Shamian J, Wilk P. Impact of structural and psychological empowerment on job strain in nursing work settings: expanding Kanter's model. Journal of nursing Administration. 2001;31(5):260-72.

[11] Mirkamali SM, Hayati.A.A., Noruzi A, Haraji N. Investigation of the relationship between Psychological empowerment and job satisfaction and organizational commitment among the employees of Tehran University. scientific-Research Journal/Education and Society,Shahed University. 2010;16(39):15-30. 
[12] Petter J, Byrnes P, Choi D, Fegan F, Miller R. Dimensions and patterns in employee empowerment: Assessing what matters to street-level bureaucrats. Journal of Public Administration Research and Theory. 2002;12(4):377-401.

[13] Chiang CF, Hsieh TS. The impacts of perceived organizational support and psychological empowerment on job performance: The mediating effects of organizational citizenship behavior. International Journal of Hospitality Management. 2012(31):180-90.

[14] Moughali A, Hasanpour A, Hasanpour M. Survrying of the relationship between employee Empowerment and Organizational commitment in of 19th districts of Tehran Education Organization. journal of public administration. 2009;1(2):119-32.

[15] Laschinger HKS, Finegan J, Shamian J. The impact of workplace organizational trust on staff nurses' work satisfaction and organization Healthcare Management Review. 2006;26(2):7023-32.

[16] Allen NJ, Meyer JP. Affective, continuance and normative commitm nt to the An examination of construct validity. Journal of Vocational Behavi 1996 19:252

[17] Cooper-Hakim A, Viswesvaran C. The construct of work com mo esting integrative framework. Psychological bulletin. 2005;131(2):241.

[18] Herrbach O. A matter of feeling? The affective tone of or izationa commitment and identification. Journal of Organizational Behavior. 2

[19] Meyer JP, Stanley DJ, Herscovitch L, Topolnytsk L. Affective, continuance, and normative commitment to the organization: A meta- alysis of antecedents, correlates, and consequences. Journal of vocational behavior. 200 1(1):20-2.

[20] Coyle-Shapiro J, Kessler I. Consequence the psyonorogical contract for the employment relationship: A large scale survey. Journal thy ment studies. 2000;37(7):903-30.

[21] Jha S. Influence of Psychological-Empowe nent on Affective, Normative and Continuance Commitment: A Study in Adia IT Ind stry. International Journal of Organisational Behaviour. 2009;15(1):53

[22] Moynihan DP, S.K. P. Me-ries at Bind: Social Networks, Person-Organization Value Fit, and turnover Int n. Journ of Public Administration Research and Theory 2008;18(2):205-2

[23] Mastracci S/. Eyaluating / Management Strategies for Recruiting and Retaining IT Profession s in th U.S, Fedcral Government. Public Personnel Management. 2009;38:19-34.

[24] Bhatnagar redicto of organizational commitment in India: strategic HR roles, org in onal ni g capability and psychological empowerment. International Journal of iman esource ranagement. 2007;18(10):1782-811.

[25] Chu ir, Y.m. The impact of work redesign and psychological empowerment on organ ional commitment in a changing environment: an example from Taiwan's stateowned iterprises. International Public Management Association for Human Resources. 2008;37:279-302.

[26] McKee M, Healy J. The role of the hospital in a changing environment. Bulletin of the World Health Organization. 2000;78(6):803-10.

[27] Yaghoubi M, Karimi S, Javadi M, Hassanzadeh A. A survey on relationship between job stress and three dimensions of organization commitment among nursing managers. Scientific Journal of Hamadan Nursing \& Midwifery Faculty. 2010;18(1):5-10.

[28] Hair J, Black B, Babin B, Anderson R, Tatham R. Multivariate Data Analysis. 6th edition ed. Upper Saddle River, USA: Prentice-Hall; 2006. 
[29] Abili K, Nastezaei N. Surveying the relationship between psychological empowerment and organizational commitment in nursing staff. TOLOO-E-BEHDASHT. 2009;8(26):26-38.

[30] Ambad A, Nabila S, Bahron A. Psychological Empowerment: The Influence on Organizational Commitment Among Employees in the Construction Sector. Journal of Global Business Management. 2012;8(2).

[31] Istomina N, Suominen T, Razbadauskas A, Martinkenas A, Kuokkanen L, Leino-Kilpi H. Lithuanian nurses' assessments of their empowerment. Scandinavian journal of caring sciences. 2012;26(1):3-11.

[32] Torabi M, Moghimi SM, Monavarian A. Investigating the Relation between Spiritual Intelligence and Psychological Empowerment among Nurses of Faghihi Hosr 2012. International Journal of Economy, Management and Social Sciences. 2013;2(8, 3:539-43,

[33] Ibrahem SZ, Elhoseeny T, Mahmoud RA. Workplace empowerment an rganizat nal commitment among nurses working at the Main University Hospital, Ilexandr Fgyp. The Journal Of The Egyptian Public Health Association. 2013;88(2):90-

[34] DeVivo D, Quinn Griffin MT, Donahue M, Fitzpatrick JJ. ceenent Among ED Nurses. Journal of Emergency Nursing. 2013.

[35] Regan LC, Rodriguez L. Nurse empowerment from a m dlemanagers' and assistant nurse managers' workplace vowerm views. The Permanente Journal. 2011;15(1):e101.

[36] Thomas KW, Velthouse BA. Cognitive elements f empowern lent: An interpretive model of intrinsic task motivation. Academy of managemen eview. 1990;15(4):666-81.

[37] Jafari V, moradi M, Ahanchi M. An exa nation of trutelationship between empowerment and organizational commitment ( $\mathrm{Ca}$ Kurdistan province electric staff). Interdisciplinary Journal of Contemporary earch n Business. 2013;4(12):860-8.

[38] Joo B-K, Shim JH. Psych rog empo terment and organizational commitment: the moderating effect of or zatic al learn, culture. Human Resource Development International. 2010;13(4 $35-$

[39] Chang L-C, Shih C in S-M. Mediating role of psychological empowerment on job satisfaction and gan ional conmitment for school health nurses: A cross-sectional questionnaire caney. Inten onal Journal of Nursing Studies. 2010;47(4):427-33.

[40] Laschinge H, F gan J, R. W. Context matters: the impact of unit leadership and empowerm nurse organizational commitment. J Nurs Adm 2009;39(5):228-35.

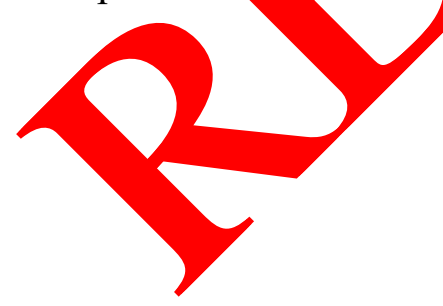

